\title{
Using Weather Records with a Forage Pro- duction Model to Forecast Range Forage Production
}

\author{
J. ROSS WIGHT, CLAYTON L. HANSON, AND DUANE WHITMER
}

\section{Abstract}

This paper describes a method for calculating site specific forecast yields and their associated probabilities of occurrence. A physically based range forage model, which utilizes beginning soil water content and daily precipitation, mean air temperature, and solar radiation as inputs, calculates the ratio of actual transpiration ( $T$ ) to potential transpiration $\left(T_{p}\right)$ as a yield index. Annual yield is calculated by the relationship: yield = potential site yield (yield when water is nonlimiting) $\times T / T_{p}$. By using the current year's beginning soil water content and weather data for a number of years, a population of yields is generated (one yield for each year of weather data). From the population of yields, a mean and various confidence intervals around the mean can be calculated as the forcast yield and its associated confidence intervals.

The forecast procedure was tested using 55 years (1917-1971) of weather records and 12 years (1967-1978) of actual yield and soil water data for an upland range site in eastern Montana. An expected two thirds of the field measured yields were within a standard deviation of the forecasted yields for the April, May, and June forecasts.

Yield forecasting is common in the agriculture industry. Forecasts help identify areas of surplus and shortage, and help establish markets. Range forage yield forecasts can be additionally beneficial in helping determine annual carrying capacities for more efficient grazing management. This is especially important during drought years when advanced warnings enable grazing adjustments to accommndate livestock needs and protect range resources from damage due to overgrazing.

Probability based yield forecasts can be made in 2 general ways: (1) the stochastic analyses of long-term yield data such as described by Hanson et al. (1982); and (2) the generation of populations of yields from which means and other distribution parameters can be calculated (Arkin et al. 1980). The first method requires long-term yield records where management has been relatively constant - no fertilization, species improvement, etc. (such records are scarce). The second method requires a population of annual weather variables and the establishment of quantitative relationships between the weather variables and plant growth. The weather variables can be obtained from weather records or generated stochastically as described by Arkin et al. (1980), Richardson (1981), or Larsen and Pense (1982).

The establishment of quantitative relationships between weather variables and plant growth has commonly been expressed in regression models such as described by Rogler and Haas (1947),

Authors are range scientist and agricultural engineer, respectively; USDA-ARS, 270 South Orchard, Boise, Ida. 83705; and range conservationist, USDI, Bureau of Land Management, P.O. Box 30157 Billings, Mont. 59107.

This article is a contribution from the Northwest Watershed Research Center, USDA-ARS, and Bureau of Land Management, USDl; in cooperation with the Agricultural Experiment Station, University of Idaho, Moscow 83843.

Manuscript received February 28, 1983.
Smoliak (1956), Currie and Peterson (1966), and Johnston et al. (1969). In their simplest form, these models are linear regression equations with forage yield as the dependent variable and annual or seasonal precipitation or available water as the independent variable (Rogler and Haas 1947). To account for the effect of the precipitation distribution during the growing season, multiple regression equations have been developed which use various combinations of monthly precipitation as the independent variables (Currie and Peterson 1966). Multiple regression models often include beginning soil water content and/or climatic parameters such as pan evaporation as independent variables (Smoliak 1956, Johnston et al. 1969). Regression models, however, are usually site specific, and thus their application is limited to the site and other environmental conditions from which the data used to develop the regression relationships were obtained.

To extend the application of regression models over a range of sites and environmental conditions, site factors, such as soil texture and soil depth, have been considered. A simple way to account for forage yield variations due to site characteristics is the use of the long-term site average yield as one of the independent variables. Such a factor integrates the total effect of site factors such as texture, slope, and species composition. The use of yield and precipitation indices as the dependent and independent variables, respectively, has provided an effective means of extending the geographical application of regression models (Sneva and Hyder 1962). These indices are the expression of the yield and precipitation variables as portions of the long-term median yields and precipitation, respectively.

In recent years, there have been increasing efforts to quantify the physical aspects of plant growth in relationship to the environment, particularly for cultivated crops. The result of these efforts has been the development of physically based plant growth and production models. The grassland simulation model, ELM (Innis 1978) and the model described by Wight and Hanks (1981) are examples of physically based models for the growth and production of range vegetation. Such models are more transferable among range sites, ecosystems, and climates than are the regression models.

This paper describes and evaluates a method of using weather records in conjunction with a physically based forage yield model to make yield forecasts with confidence intervals and stated probabilities of occurrence. The forecast method is similar to that used by Arkin et al. (1980) to forecast the growth and yield of sorghum, except that the weather variables were obtained directly from weather records rather than from stochastic generation.

\section{Methods and Procedures}

A forage production model known as ERHYM (Wight and Neff 1983) was used to relate soil water and climatic parameters to plant 
growth. Using the soil water content in the root zone at the beginning of the growing season, daily precipitation, and estimates of potential evapotranspiration (calculated from solar radiation and daily mean temperature) as inputs, the model calculates daily soil water content, actual transpiration $(T)$, and potential transpiration $\left(T_{p}\right)$. Total herbage yield at peak standing crop is calculated from the relationship: $Y / Y_{p}=T / T_{p}$, where $Y$ is actual yield and $Y_{p}$ is the potential site yield. The model's output, $T / T_{p}$, provides an effective means of indexing the growing seasons's climatic effect on yield. This index accounts for the amount of precipitation, its distribution, associated evaporative demand, and soil water content. Note, that when water is nonlimiting, $T / T_{p}=1.0$. The yield index can be expressed in terms of the long-term average site yield rather than site potential using the relationship: Yield index $=1.5 \mathrm{~T} / \mathrm{T}_{\mathrm{p}}$. Previously reported research (Wight and Black 1971) indicates that in the northern Great Plains, the site potential yield is about 1.5 times the long-term site average yield.

To forecast the current year's forage production or yield index, the model is run using the available soil water content at the beginning of the growing season and daily precipitation, mean air temperature, and solar radiation data from weather records. Each model run produces a yield index $\left(T / T_{p}\right)$ based on the current year's actual beginning soil water content, and the growing season's precipitation, daily temperature, and solar radiation from a past year's weather record. For example, to forecast 1983 forage yields, the soil water content at the beginning of the 1983 growing season would be used with each model run. If 50 years of weather data were available, the model could be run 50 times, once for each year, producing a population of 50 yields or yield indices. Thus, the 50 yields or yield indices reflect the same beginning soil water content but the variability of the 50 different weather records. The mean of these 50 yields or yield indices is the 1983 forecast value. This forecast can be made at the beginning of the growing season when only the current soil water conditions are known.

Assuming that the yield indices are normally distributed, their mean and standard deviation can then be calculated and probability statements can be made as to the occurrence of the forecasted yield within specified intervals. For example, if the mean of 50 model runs was $1,000 \mathrm{~kg}$ forage/ ha and the standard deviation was $300 \mathrm{~kg}$ forage/ ha, we could state that there was a $68 \%$ probability that the 1983 forage yield for that particular site would be between
700 and $1,300 \mathrm{~kg} / \mathrm{ha}$.

The same procedure can be used to update the forecasts during the growing season based on soil water content at the time of the forecast. These soil water contents can be determined by field measurements or from model-predicted soil water values which are available when the model is run with real-time or forecast year weather data. Field-measured soil water values are necessary only for the initial simulation or forecast of a year.

If solar radiation records are not available, solar radiation values can be adequately estimated from solar radiation curves or solar tables. The model can be run for as many years as there are weather records. Arkin et al. (1980) found that 50 years provided an adequately large population from which to calculate a mean and other distribution parameters for forecasting sorghum yields.

We tested this forecast procedure on a mixed prairie range site for which we had 12 years (1967-1978) of soil water and yield data (see Wight and Hanks 1981). The study site was located near Sidney, Mont., on a sandy loam range site with a 1 to $2 \%$ slope. The major forage species included western wheatgrass (Agropyron smithii), blue grama, (Bouteloua gracilis), needleandthread grass (Stipa comata), threadleaf sedge (Carex filifolia), and needleleaf sedge (Carex eleocharis). Annual herbage yields (Table 1) were measured at peak standing crop, which usually occurred about mid-July.

Weather records were available from nearby Glendive, Mont., for the period 1917-1971. This 55-year record enabled us to generate a population of 55 yield indices for each forecast. Solar radiation values were estimated from a curve of mean daily solar radiation developed from monthly mean daily solar radiation data from Sidney, Mont., for the period 1967-1976 (Fig. 1). Yield indices generated with estimated solar radiation values were compared with those generated with actual daily solar radiation values for the 1967-1978 period. Differences in the yield indices averaged less than 0.03 and ranged from 0.0 to 0.07 , indicating that the estimated solar radiation values were adequate for forage yield forecasting.

Yield indices were calculated for the 12 growing seasons (1967-1978). Previous research (Wight and Hanks 1981) showed that, in terms of predicting peak standing crop, the model was not sensitive to small variations in growing season lengths; therefore, a fixed growing season of April 1 to July 15 was used for all years. Use of a fixed growing season enhanced the demonstration of the

Table 1. Forecasted and field-measured yields, sample size, and available soil water content at the beginning of the growing season for a range site near Sidney, Montana.

\begin{tabular}{|c|c|c|c|c|c|c|c|c|c|}
\hline \multirow[b]{2}{*}{ Year } & \multicolumn{5}{|c|}{ Forecasted } & \multicolumn{2}{|c|}{ Field-measured } & \multirow[b]{2}{*}{$\mathbf{N}$} & \multirow[b]{2}{*}{$\begin{array}{l}\text { Soil water } \\
\text { (cm) }\end{array}$} \\
\hline & April 1 & May 1 & $\begin{array}{l}\text { June } 1 \\
\mathrm{~kg} / \mathrm{ha}\end{array}$ & July 1 & July 15 & $\begin{array}{l}\text { Pcak standing } \\
\text { crop }\end{array}$ & $\begin{array}{l}\text { Standard } \\
\text { deviation }\end{array}$ & & \\
\hline 1967 & 780 & 1053 & 1014 & 1170 & 1170 & 1200 & 278 & 8 & 4.4 \\
\hline 1968 & 715 & 572 & 455 & 702 & 676 & 742 & 51 & 8 & 3.5 \\
\hline 1969 & 1014 & 1092 & 1066 & 1209 & 1209 & 1245 & 237 & 14 & 10.7 \\
\hline 1970 & 793 & 1040 & 1196 & 1235 & 1235 & 1205 & 217 & 20 & 5.1 \\
\hline 1971 & 844 & 832 & 767 & 767 & 741 & 720 & 166 & 24 & 4.9 \\
\hline 1972 & 1092 & 1105 & 1261 & 1300 & 1300 & 1215 & 241 & 24 & 13.6 \\
\hline 1973 & 728 & 884 & 806 & 1157 & 1157 & 763 & 208 & 24 & 4.2 \\
\hline 1974 & 1040 & 975 & 1209 & 1274 & 1261 & 933 & 204 & 24 & 8.8 \\
\hline 1975 & 754 & 988 & 1053 & 1261 & 1248 & 1321 & 263 & 24 & 13.6 \\
\hline 1976 & 910 & 1014 & 1079 & 1196 & 1196 & 1100 & 266 & 24 & 7.3 \\
\hline 1977 & 988 & 819 & 715 & 624 & 585 & 450 & 166 & 18 & 8.3 \\
\hline 1978 & 962 & 832 & 1235 & 1235 & 1248 & 1246 & 401 & 16 & 7.2 \\
\hline Mean & 885 & 933 & 988 & 1094 & 1085 & 1012 & 225 & 19 & 7.6 \\
\hline $\mathrm{S}^{2}$ & 312 & 250 & 169 & 26 & - & 225 & & & \\
\hline
\end{tabular}

$\mathrm{I}$ is the number of $0.5 \times 2.0 \mathrm{~m}$ sampling quadrats used to measure yield

is is the mean of the annual standard deviations for the 12 years. Each yield value in the table has a corresponding standard deviation. 


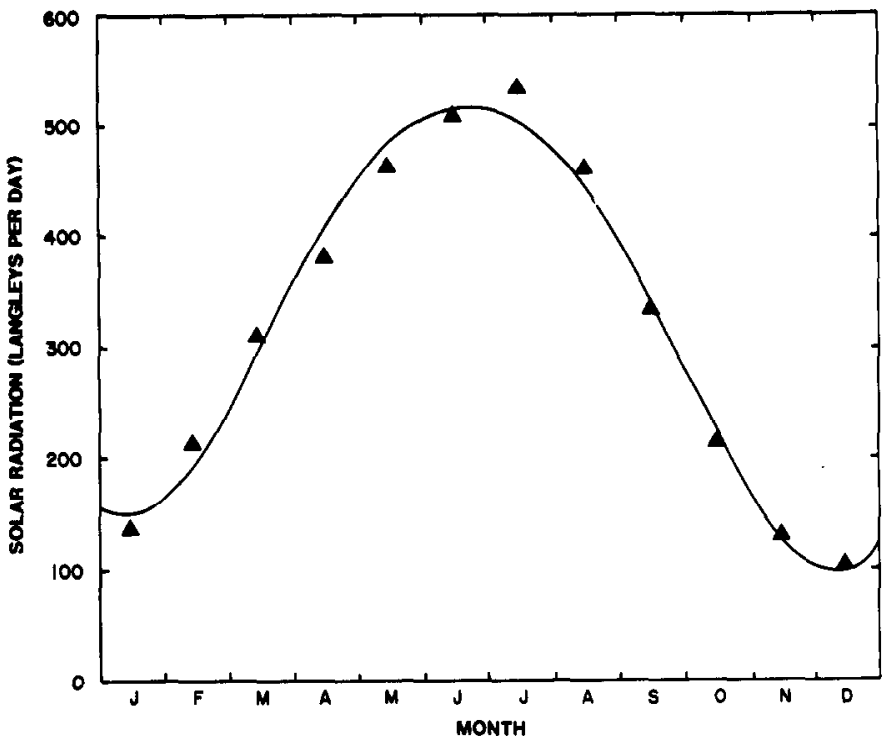

Fig. 1. Average annual solar radiation curve for eastern Montana.

forecast procedure and the model-predicted yields were only slightly different from those originally reported by Wight and Hanks (1981). The initial forecast each year was made April 1 and was based on yield indices generated by the forage production model using actual soil water content data on April 1 and 55 years of weather data (daily precipitation and mean air temperature). A yield index was calculated for each year of the 55 years of weather data. From the resulting population of yield indices, a mean and standard deviation was calculated and used to determine the forage yield forecast for that forecast year. Yield forecasts were updated May 1, June 1, July 1, and July 15 using the same procedure, except that the current year's or forecast year's weather data were used for the period April 1 to date of forecast and the 55 years of weather data was used from the date of forecast to the end of the growing season. Yield index distributions were compared to normal distributions using standard-normal plots, and the Kolmogorov-Smirnov goodness of fit test (Yevjevich 1972).

\section{Results and Discussion}

Standard-normal plots of the 55 yield indices for a random sample of yield forecasts were similar to the plot in Fig. 2, indicating that the yield indices were approximately normally distributed. Only for the July 1 forecasts did the distribution of yield indices indicate a significant departure $(\alpha=.05)$ from normality, according to the Kolmogorov-Smirnov test. In calculating the population of yield indices for each forecast, only the weather data input varied from year to year. As the forecast date approached the harvest date, the historical data input became an increasingly smaller portion of the total and represented only 15 of 106 days of input on the July 1 forecast date. Therefore, the standard deviations of the yield forecasts were small and slight distortions in the distribution would indicate a statistically significant departure from normality.

Forecast yields for each date for each year are presented in Table 1. Each forecast yield was determined from the mean of the 55 yield indices calculated for each year of weather record. The potential yield for the study site was about $1300 \mathrm{~kg} / \mathrm{ha}$ (Wight and Hanks 1981) and actual yields were calculated from the yield indices using the relationship: $Y=Y_{p} T / T_{p}$. The harvest date (July 15) forecasts or model-predicted yields were calculated entirely from actual or current year's soil water and weather data, and are, thus, a measure

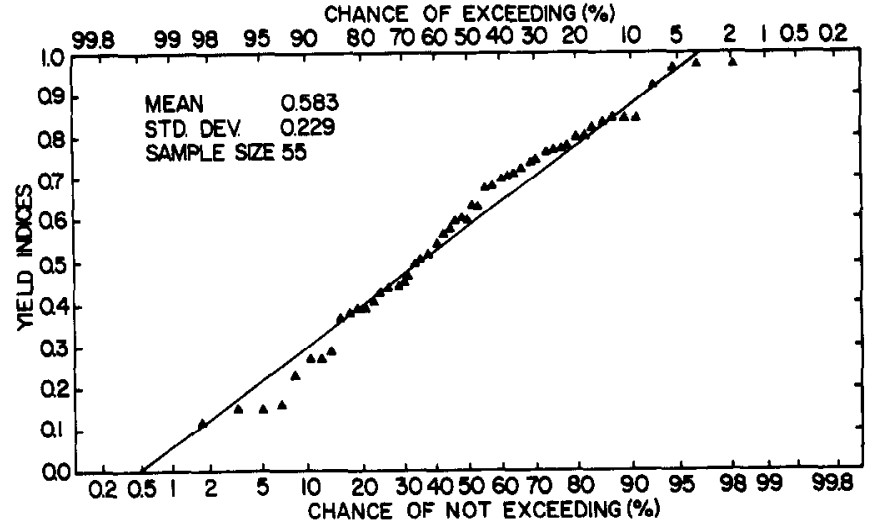

Fig. 2. Standard-normal plot of 55 yield indices that were calculated from 1917-1971 historical weather records and used to make the April 1 yield forecast for 1967.

of the model's ability to predict annual yield.

As would be expected, the standard deviations decreased as the forecast date approached the harvest date (Table 1). Averaged over the 12 years, the standard deviations were $312,250,169$, and 26 $\mathrm{kg} /$ ha for the April 1, May 1, June 1, and July 1 forecast dates, respectively. There was little variation in standard deviations among years. For the April 1 forecast, 11 of the 12 standard deviations were within a $260-351 \mathrm{~kg} / \mathrm{ha}$ range. In 1972 , a nearly saturated soil water profile significantly reduced the yield variation over the 55 years and the forecast standard deviation was only 208 $\mathrm{kg} / \mathrm{ha}$.

While somewhat inadequate in sample size, the occurrence of the 12 years of actual (field-measured) yields in relationship to the forecasted yields and their standard deviations provide an indication of the validity of the forecast procedure. In a normal population, $68 \%$ of the observations will occur within plus or minus one standard deviation of the population mean. Thus, for each forecast date, 8 of the 12 actual yields (assuming the model is without error) should have been within plus or minus one standard deviation of the forecasted yield. By comparing the April 1, May 1, June 1, and July 1 forecasted yields with the harvest date, model-predicted yields, we evaluated the forecast procedure under the assumption that the model was without error. For the April 1, May 1, June 1, and July 1 forecast dates, $7,10,11$, and 10 harvest date, modelpredicted yields, respectively, were within the standard deviations of the forecast yields. Only for the April 1 forecasts was the occurrence of the harvest date, model-predicted yields within the standard deviations of the forecast yields less than the 8 expected for a normal distribution.

A more practical evaluation is a comparison of field-measured or actual yields with the forecasted yields. This provides a test of both the model and the forecast procedure. As indicated in Table 2, actual yields were generally within the standard deviations of the forecasted yields the expected $68 \%$ of the time. Occurrences of the

Table 2. Number of field-measured yields that were within the indicated intervals of the forecasted yields for the 12-year period, 1967-1968, Sidney, Montana.

\begin{tabular}{lccc}
\hline Forecast date & \pm Std. Dev. & $\pm 250 \mathrm{~kg} / \mathrm{ha}$ & $\pm 25 \%$ of Mean \\
\hline April 1 & 8 & 7 & 7 \\
May 1 & 9 & 9 & 8 \\
June I & 8 & 9 & 10 \\
July 1 & 5 & 10 & 9 \\
\hline
\end{tabular}




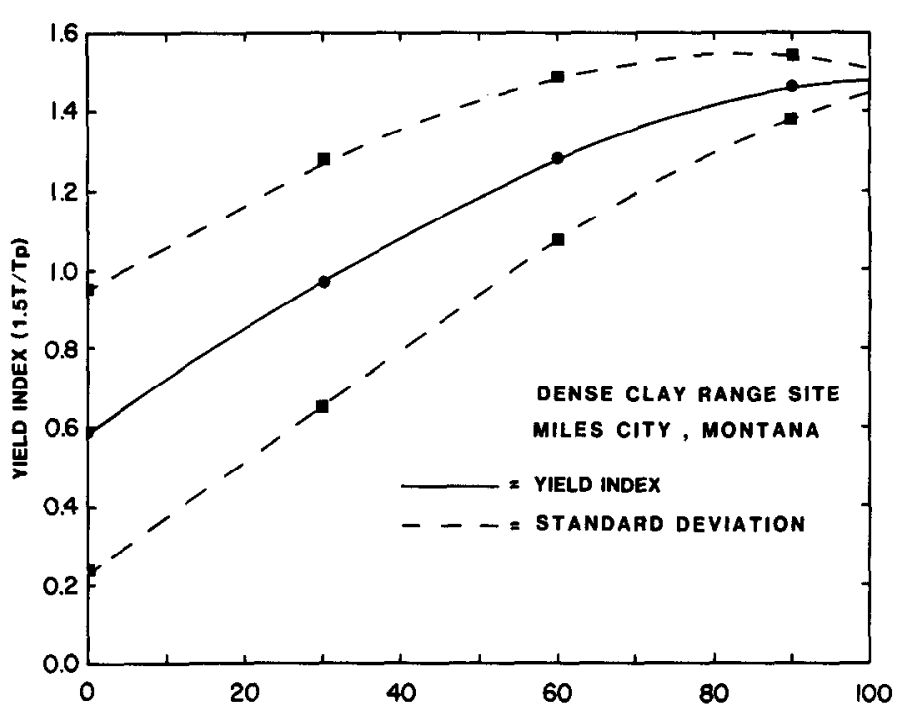

BEGINNING SOIL WATER (PERCENT OF AVAILABLE WATER HOLDING CAPACITY)

Fig. 3. Relationship of the forecasted yield index to beginning soil water content for a dense clay range site near Miles City, Montana.

actual yields within a plus or minus $250 \mathrm{~kg} / \mathrm{ha}$ and a plus or minus $25 \%$ interval around the forecasted yeild are also presented in Table 2.

\section{Application}

Annual yield forecasts can be made using a yield predicting model that utilizes weather variables as the independent or driving variables and a population of annual weather records from a nearby weather station. The ERHYM model (Wight and Neff 1983) used in this study has the forecast procedure as an option. This model was used in 1981 to forecast yields for over 40 U.S. Department of Interior, Bureau of Land Management managed range sites in central and eastern Montana.

A more practical application of the forecast procedure is demonstrated in Figure 3 where forecasted yield indices are plotted against a range of beginning soil water contents for a specific range site. The yield indices in Figure 3 were calculated in terms of the long-term average yield for a dense clay range site near Miles City, Mont. Current year yield forecasts for this site can be determined by measuring the beginning soil water content and locating the appropriate yield index on the curve in Figure 3. For example, if the beginning soil water content was $20 \%$ (this is available soil water), the yield index would be about 0.85 with a standard deviation of 0.33 . Thus we would forecast a yield that was $85 \%$ of the long-term average. If the soil water profile was nearly saturated at the beginning of the growing season, then a yield index of about
1.40 with a standard deviation of 0.08 would be expected. A series of charts, such as this, with beginning soil water measurements could be used to make annual yield forecasts.

It should be noted that when stochastic weather generation methods are available, they are an excellent means of providing the climatic variables. Stochastic generation is particularly valuable when weather records are limited. Also, the distribution of mode] generated yields can be used to determine more than means and standard deviations. As pointed out by Arkin et al. (1980), these distributions can be used to determine: "(1) the probability that a certain yicld value might occur, (2) the most likely occurring yield. (3) the greatest and smallest occurring yield, (4) the probabilities that the yield may be greater or smaller than a particular value, (5) the average yield value expected over many years, and (6) the expected year-to-year variability in yields over many years."

\section{Literature Cited}

Arkin, G.F., S.J. Maas, and C.W. Richardson. 1980. Forecasting grain sorghum yields using simulated weather data and updating techniques. Trans. Amer. Soc. Agr. Engin. 23:676-680.

Currie, P.O., and G. Peterson. 1966. Using growing season precipitation to predict crested wheatgrass yields. J. Range Manage. 19:284-288.

Hanson, C.L., J.R. Wight, J.P. Smith, and S. Smoliak. 1982. Use of historical yield data to forecast range herbage production. J. Range Manage. 35:614-616.

Innis, G.S. (Ed.). 1978. Grassland simulation model. Ecological Studies 26, Springer-Verlag, New York, p. 1-298.

Johnston, A., Smoliak, A.D. Smith, and L.E. Lutwick. 1969. Scasona] precipitation, evaporation, soil moisture, and yield of fertilized range vegetation. Can. J. Plant Sci. 49:123-128.

Larsen, G.A., and R.B. Pense. 1982. Stochastic simulation of daily climatic data for agronomic models. Agron. J. 74:510-514.

Richardson, C.W. 1981. Stochastic simulation of daily precipitation, tem. perature, and solar radiation. Water Resour. Res. 17:182-190.

Rogler, G.A., and H.J. Haas. 1947. Range production as related to soil moisture and precipitation on the northern Great Plains. J. Amer. Soc. Agron. 39:378-389.

Smoliak, S. 1956. Influence of climatic conditions on forage production of shortgrass rangeland. J. Range Manage. 9:89-91.

Sneva, F.A., and D.N. Hyder. 1962. Estimating herbage production on semiarid ranges in the intermountain region. J. Range Manage. 15:88-93.

Wight, J.R., and A.L. Black. 1971. Yield potentials of rangelands as related to nutrient and soil water availabiltiy, p. 48-54. In: Proc., Annu. Pacific Northwest Fertilizer Confer., July 13-15, Bozeman, Mont. Pacific Northwest Plant Food Assoc., Portland, Ore.

Wight, J.R., and R.J. Hanks. 1981. A water-balance, climate model for range herbage production. J. Range Manage. 34:307-311.

Wight, J.R., and E.L. Neff. 1983. Soil-Vegetation-Hydrology Studies, Vol. II. User manual for ERHYM: The Ekalaka Rangeland Hydrology and Yield Model. USDA, ARS, Agr. Res. Ser., ARR-W-29/Jan. 1983.

Yevjevich, V. 1972. Probability statistics in hydrology. Water Resour. Pub., Fort Collins, Colo. 